\title{
Poor Dietary Protein Intake in Elderly Population with Sarcopenia and Osteosarcopenia: A Nationwide Population-Based Study
}

\author{
Jun-II Yoo ${ }^{1, *}$, Kyung-Hag Lee ${ }^{2, *}$, Yonghwan Choi ${ }^{3}$, Jaehwang Lee ${ }^{3}$, Yong-Geun Park \\ 'Department of Orthopaedic Surgery, Gyeongsang National University Hospital, Gyeongsang National University, Jinju; \\ ${ }^{2}$ Department of Orthopaedic Surgery, National Medical Center, Seoul; \\ ${ }^{3}$ Department of Orthopaedic Surgery, Jeju National University Hospital, Jeju National University School of Medicine, Jeju, Korea
}

\author{
Corresponding author \\ Yong-Geun Park \\ Department of Orthopaedic Surgery, Jeju \\ National University Hospital, Jeju National \\ University School of Medicine, \\ 15 Aran 13-gil, Jeju 63241, Korea \\ Tel: +82-64-717-2710 \\ Fax: +82-64-717-1697 \\ E-mail: pyk184@hanmail.net; \\ cellulosae@naver.com
}

Received: October 30, 2020

Revised: November 13, 2020

Accepted: November 15, 2020

*Jun-II Yoo and Kyung-Hag Lee contributed equally to this work and should be considered co-first authors.
Copyright $@ 2020$ The Korean Society for Bone and Mineral Research

This is an Open Access article distributed under the terms of the Creative Commons Attribution Non-Commercial License (https://creativecommons.org/licenses/by-nc/4.0/) which permits unrestricted non-commercial use, distribution, and reproduction in any medium, provided the original work is properly cited.

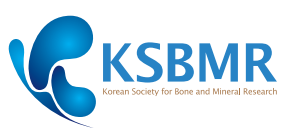

Background: Our purpose in this study was to evaluate any deficiency of protein intake for different types of sarcopenia, including osteosarcopenia and sarcopenic obesity and to establish a cut-off value for the relationship between malnutrition, sarcopenia, and osteosarcopenia. Methods: The cross-sectional study was performed using data from the Korea National Health and Nutrition Examination Survey. A total of 4,020 participants (men, 1,698 and women, 2,322) were analyzed in the present study. Sarcopenia is defined according to the criteria for the Asia Working Group for Sarcopenia. To evaluate the adequacy of protein intake, the value obtained by dividing the amount of protein consumed through food by the daily recommended protein amount ( $50 \mathrm{~g} /$ day) of Korean males was defined as the nutrient intake ratio. Results: Total protein $(P<0.001$ in men, $P<0.001$ in women) and low dietary intake protein $(P<0.001$ in men, $P=0.046$ in women) were significantly lower in the sarcopenia group than in the normal group, and were significantly lower in the osteosarcopenia group than in the normal group for both men and women. The cut-off value of the adjusted weight of protein intake for sarcopenia was $0.58 \mathrm{~g} / \mathrm{kg} /$ day in men and $0.98 \mathrm{~g} / \mathrm{kg} /$ day in women. The cut-off value for adjusted weight of protein intake for osteo-sarcopenia was $0.8 \mathrm{~g} / \mathrm{kg} /$ day in men and $0.5 \mathrm{~g} / \mathrm{kg} / \mathrm{day}$ in women. Conclusions: A comprehensive dietary assessment to detect nutritional deficits that predispose one to or aggravate muscle atrophy is important for establishing a treatment plan for patients with malnutrition.

Key Words: Aged · Dietary proteins · Osteoporosis · Sarcopenia

\section{INTRODUCTION}

Sarcopenia had its own the International Classification of Diseases, Tenth Revision, Clinical Modification (ICD-10-CM). The assigned code was M62.84, which has been available for use since 2016. Recently, many studies related to sarcopenia have been reported during the last decades.

As one possible mechanism of sarcopenia that would explain the decrease of muscle mass, a deficit between protein synthesis and its degradation has been considered to be an important causal factor that results in malnutrition.[1] In fact, malnutrition is frequently found in various patient populations, particularly older adults, and in medical conditions, such as in patients with sarcopenia.[2] Sarcope- 
nia studies have focused on metabolic diseases, such as diabetes, obesity, and cachexia, and on some specific diseases, including chronic renal failure, congestive heart failure, and chronic obstructive pulmonary disease. Of them, osteosarcopenia and sarcopenic obesity are representative type of sarcopenia.[3,4] Several studies have reported that patients with malnutrition and sarcopenia were associated with increased morbidity, increased infection, and high rates of falls and disability.[5-8]

Although pharmacologic intervention in patients with sarcopenia have been introduced, many medications are currently undergoing clinical trials. Only nonpharmacological intervention, including exercise and nutritional supports, are currently available and have reported successful outcomes.[9-12] Now, estimation of nutritional status is most important for successful treatment of sarcopenia. However, the nutritional status of patient with sarcopenia has not been sufficiently studied. In addition, the nutritional status depending on the type of sarcopenia, including osteosarcopenia and sarcopenic obesity, have not been evaluated. Therefore, our purpose in this study was to evaluate any deficiency of protein intake for the different type of sarcopenia and to establish a cut-off value for the relationship between malnutrition, sarcopenia, and osteosarcopenia.

\section{METHODS}

\section{Participants}

This study was based on data from the 2008 to $2011 \mathrm{Ko}$ rea National Health and Nutrition Examination Survey (KNHANES), which was conducted by the Korean Ministry of Health and Welfare. KNHANES has been a nationwide representative cross-sectional survey for the Korean population with a clustered, multistage, stratified, and rolling sampling design. KNHANES consists of 3 sections: a health interview, a health examination, and a dietary survey. The survey data is collected via household interviews and by direct standardized physical examinations conducted in specially equipped mobile examination centers. The data was collected from 37,753 participants from survey years $2008(n=9,744), 2009(n=10,533), 2010(n=8,958)$, and $2011(n=8,518)$. Participants were excluded if they were under the age of 65 , or if data were not available to evaluate skeletal muscle mass or dietary intake. After these exclusions, we analyzed a total of 4,020 participants (men,

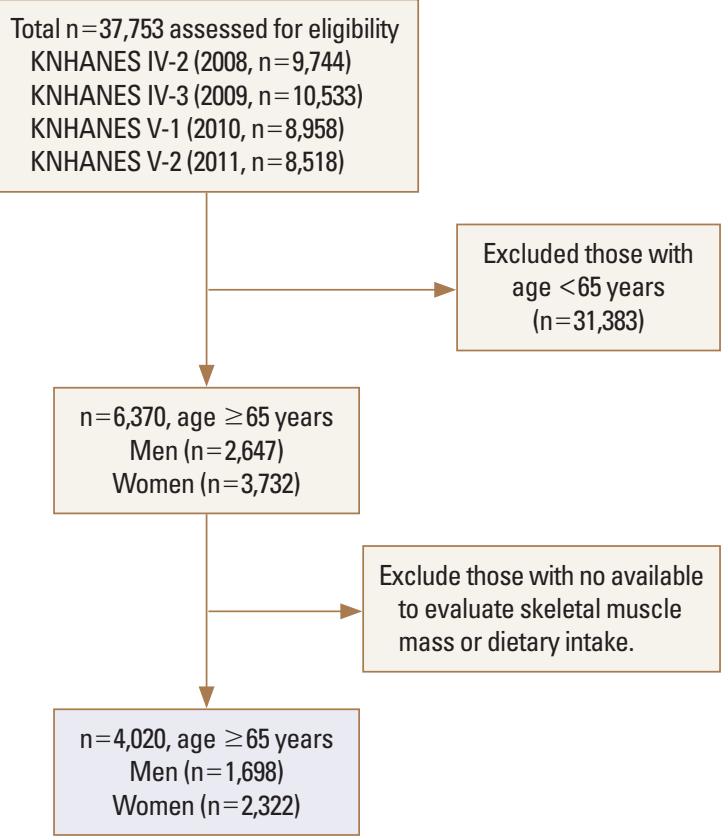

Fig. 1. Selection process of study subjects, the Korea National Health and Nutrition Examination Survey (KNHANES) IV and V (2008-2011).

1,698 and women, 2,322) for this study (Fig. 1).

\section{Health examination survey}

A health questionnaire was used to obtain information on age, gender, income (\% of highest quartile), education status (\% of more than middle-school graduation), smoking status (current or non-current smoker), moderate physical activity, and walking activity (yes or no). Moderate physical activity was defined as 5 or more days of moderately intense activity for at least $30 \mathrm{~min} /$ day. Walking physical activity was defined as 5 or more days of walking for at least $30 \mathrm{~min} /$ day. Body weight and height were measured in light clothing with no shoes, and body mass index (BMI) was calculated as weight $(\mathrm{kg})$ divided by height squared $\left(\mathrm{m}^{2}\right)$. Information about comorbidities, including diabetes, chronic obstructive pulmonary disease, chronic renal failure (CRF), and malignancy, as potential confounding factors were examined by means of the health interview survey.

\section{Dietary intake variable}

Dietary intake was assessed by trained staff using a complete 24-hr recall method. Daily intake of energy, carbohydrates, fat, and protein was calculated by referencing nutrient concentrations in foods according to the Korean food composition table.[13] 


\section{Nutrient adequacy ratio (NAR)}

To evaluate the adequacy of protein intake, the NAR was used. The amount of protein consumed as food was divided by the daily recommended protein amount ( $50 \mathrm{~g} /$ day) of Korean males; the result was defined as NAR. In NAR, 1.0 was set as the highest upper limit; values above 1.0 were treated as 1.0, whereas values below 1.0 were used as they were.

\section{Body composition}

Body composition in the KNHANES was measured by whole-body dual energy X-ray absorptiometry (DXA; QDR 4500A; Hologic Inc., Bedford, MA, USA). All subjects changed into paper gowns and were asked to remove all jewelry and other personal effects that could interfere with the DXA examination. To obtain accurate and reliable results, all data regarding body composition were gathered by educated and quality controlled sarcopenia examination surveyors. [14] Bone mineral content, fat mass, and lean soft-tissue mass were measured separately for each part of the body, including the arms and legs. The lean soft-tissue masses of the arms and legs were nearly equal to the skeletal muscle mass. As absolute muscle mass correlates with height, the skeletal muscle mass index (SMI) was calculated by the following formula: (lean mass $[\mathrm{kg}] /$ height $\left[\mathrm{m}^{2}\right]$ ), which is directly analogous to $\mathrm{BMI}\left(\mathrm{BMI}=\right.$ weight $[\mathrm{kg}] /$ height $\left.\left[\mathrm{m}^{2}\right]\right)$. Arm SMI was defined as (arm lean mass $[\mathrm{kg}] /$ height $\left[\mathrm{m}^{2}\right]$ ). Leg SMI was defined as (leg lean mass $[\mathrm{kg}] /$ height $\left[\mathrm{m}^{2}\right]$ ). Appendicular SMI was defined as the sum of the arm and leg SMls. Sarcopenia was defined according to the criteria for the Asian Working Group for Sarcopenia (AWGS; SMI of below $5.4 \mathrm{~kg} / \mathrm{m}^{2}$ in women and below $7.0 \mathrm{~kg} / \mathrm{m}^{2}$ in men). [15] Osteoporosis was defined as a BMD 2.5 standard deviations below the peak bone mass of a young, healthy, gender- and race-matched reference population according to the World Health Organization diagnostic classification. The cut-off point of BMI for obesity was greater than or equal to $25 \mathrm{~kg} / \mathrm{m}^{2}$ on the basis of the Asian Pacific criterion. Osteosarcopenia was defined as the co-presence of sarcopenia and osteoporosis. Sarcopenic obesity was defined as the co-presence of sarcopenia and obesity.

\section{Statistical analysis}

We used complex sample analyses in this study to correct for the distributions of the cluster samples regarding the primary sampling unit, covariance, and significance to correspond with those of the general Korean population. The target population for the sampling procedure in the KNHANES was residents of Korea. However, residents of nursing homes, military facilities, and prisons were excluded. In order to improve the accuracy of the nationwide representative data, the sample design was carried out in a 3-year cycle (according to the time of year). Also, a survey of household members was conducted for the sample area, and the number of residential households was extracted by means of the sample design. We selected 20 households as the sample size. All analyses were carried out with the sample weights of KNHANES.

A rolling sampling survey is one in which independent rolling samples $(n=F)$, not overlapping with the entire sample, are established and compared. In this case, each rolling sample was extracted in such a way that the probability distribution should be the sampling ratio of $f=1 / F$ for the entire sample. Therefore, at the time of passing the Fth cycle, the accumulated samples surveyed for the entire time will be organized into a sample survey for the entire population.

Protein intake adjusted body weight $(\mathrm{g} / \mathrm{kg})$ was categorized separately as follows: Men $(\mathrm{Q} 1<0.67,0.67 \leq \mathrm{Q} 2$ $<0.90,0.90 \leq \mathrm{Q} 3<1.22, \mathrm{Q} 4 \geq 1.22)$ and Women $(\mathrm{Q} 1<0.53$, $0.53 \leq \mathrm{Q} 2<0.75,0.75 \leq \mathrm{Q} 3<1.02, \mathrm{Q} 4 \geq 1.02$ ). Low dietary protein was assumed to be less than $55 \mathrm{~g} /$ day for men and less than $45 \mathrm{~g} /$ day for women according to the recommended nutritional value of Koreans.[16]

The Student's $t$-test and the $\chi^{2}$ test were performed to compare means and proportions between each group. Receiver operating characteristic curve were used to determine the cut off values of protein intake for sarcopenia and osteosarcopenia. All statistical tests were 2-tailed, and statistical significance was defined as $P$ less than 0.05 . The statistical calculation was performed using SPSS Statistics version 22 (SPSS Inc., Chicago, IL, USA).

\section{RESULTS}

\section{Characteristics of elderly Korean population older than 65 years by presence of sarcopenia}

In the elderly men, age $(P=0.006)$, moderate physical activity $(P=0.043), \operatorname{CRF}(P=0.01)$, and malignancy $(P<$ 
0.001) were significantly higher in the sarcopenia group than in the normal group. Although the levels of parathyroid hormone and alkaline phosphatase were significantly higher in the sarcopenia group, the vitamin D and hemoglobin levels were significantly lower. In the elderly women, age was significantly higher in the sarcopenia group than in the normal group $(P<0.001)$. However, $\mathrm{BMI}(P<$ $0.001)$, appendicular SMI $(P<0.001)$, hemoglobin $(P<0.01)$, and triglyceride $(P=0.01)$ were significantly lower in the sarcopenia group than in the normal group (Table 1).

\section{Dietary intake of total energy, carbohydrates,} fats, and proteins by presence of Sarcopenia

In the elderly men, total energy $(P<0.001)$, carbohydrates $(P<0.001)$, fat $(P=0.001)$, total protein $(P<0.001)$, and low dietary protein intake $(P<0.001)$ were significantly lower in the sarcopenia group than in the normal group.

In elderly women, total energy $(P<0.001)$, carbohydrates $(P<0.001)$, fat $(P=0.009)$, total protein $(P<0.001)$, and low dietary protein intake $(P=0.046)$ were significantly lower in the sarcopenia group than in the normal group (Table 2).

\section{Dietary intake of total energy, carbohydrates, fats, and proteins by presence of osteosarcopenia}

In the elderly men, total energy $(P<0.001)$, carbohydrates $(P<0.001)$, fat $(P<0.001)$, total protein $(P<0.001)$, and low dietary protein intake $(P<0.001)$ were significantly lower in the osteosarcopenia group than In the normal group.

Table 1. Characteristics of elderly Korean older than 65 years by presence of sarcopenia

\begin{tabular}{|c|c|c|c|c|c|c|}
\hline \multirow{2}{*}{ Variables } & \multicolumn{3}{|c|}{ Men } & \multicolumn{3}{|c|}{ Women } \\
\hline & Normal $(n=1,190)$ & Sarcopenia $(n=508)$ & $P$-value & Normal $(n=2,071)$ & Sarcopenia $(n=251)$ & $P$-value \\
\hline Age (yr) & $71.3 \pm 4.9$ & $73.8 \pm 5.4$ & 0.006 & $72.3 \pm 5.4$ & $74.2 \pm 6.3$ & $<0.001$ \\
\hline Weight $(\mathrm{kg})$ & $65.3 \pm 8.6$ & $56.8 \pm 8.8$ & $<0.001$ & $55.8 \pm 8.7$ & $46.9 \pm 6.8$ & $<0.001$ \\
\hline $\mathrm{BMI}\left(\mathrm{kg} / \mathrm{m}^{2}\right)$ & $23.9 \pm 2.6$ & $20.9 \pm 2.7$ & 0.232 & $24.5 \pm 3.3$ & $20.9 \pm 2.5$ & $<0.001$ \\
\hline Appendicular SMI $\left(\mathrm{kg} / \mathrm{m}^{2}\right)$ & $7.9 \pm 0.6$ & $6.3 \pm 0.6$ & 0.092 & $6.5 \pm 1.0$ & $5.0 \pm 0.3$ & $<0.001$ \\
\hline \multicolumn{7}{|l|}{ Lifestyle factors (\%) } \\
\hline Education ${ }^{\mathrm{al}}$ & 31.6 & 30.5 & 0.368 & 6.8 & 8.3 & 0.499 \\
\hline Smoking status ${ }^{\mathrm{b})}$ & 58.2 & 54.1 & 0.312 & 8.6 & 10.9 & 0.245 \\
\hline Moderate physical activityc) & 13.4 & 9.6 & 0.043 & 12.8 & 8.6 & 0.064 \\
\hline Walking physical activityd) & 54.6 & 50.0 & 0.161 & 40.0 & 38.0 & 0.561 \\
\hline Income $e^{\mathrm{e})}$ & 26.1 & 23.0 & 0.302 & 25.4 & 27.5 & 0.711 \\
\hline \multicolumn{7}{|l|}{ Comorbidity (\%) } \\
\hline Diabetes & 16.7 & 19.5 & 0.118 & 17.8 & 17.0 & 0.352 \\
\hline COPD & 0.0 & 1.2 & 0.349 & 0.5 & 0.0 & 0.892 \\
\hline Chronic renal failure & 0.5 & 0.8 & 0.010 & 0.7 & 0.8 & 0.053 \\
\hline Malignancy & 5.2 & 9.6 & $<0.001$ & 5.6 & 6.4 & 0.641 \\
\hline \multicolumn{7}{|l|}{ Blood biomarkers } \\
\hline PTH & $66.7 \pm 28.7$ & $69.3 \pm 28.5$ & $<0.010$ & $73.1 \pm 36.0$ & $72.4 \pm 55.3$ & 0.854 \\
\hline VitD & $22.3 \pm 7.6$ & $20.8 \pm 7.8$ & 0.010 & $19.2 \pm 7.5$ & $18.8 \pm 7.4$ & 0.512 \\
\hline ALP & $241.1 \pm 76.1$ & $267.6 \pm 91.0$ & $<0.010$ & $258.6 \pm 81.1$ & $257.6 \pm 85.7$ & 0.879 \\
\hline Hemoglobin & $14.6 \pm 1.2$ & $14.1 \pm 1.6$ & $<0.010$ & $13.0 \pm 1.1$ & $12.7 \pm 1.2$ & $<0.010$ \\
\hline $\mathrm{TG}$ & $142.6 \pm 95.5$ & $130.4 \pm 85.3$ & 0.010 & $148.5 \pm 86.3$ & $137.9 \pm 74.8$ & 0.010 \\
\hline Fasting glucose & $104.6 \pm 26.5$ & $105.9 \pm 34.2$ & 0.375 & $103.2 \pm 23.5$ & $103.1 \pm 32.9$ & 0.961 \\
\hline
\end{tabular}

The data is presented as mean \pm standard deviation or percentage distribution of participants as appropriate. Significance was compared between nonsarcopenia and sarcopenia groups using Student's $t$-test or Pearson $\chi^{2}$ test. The unweighted sample size is presented in the table, but the results reflect the weighted sample.

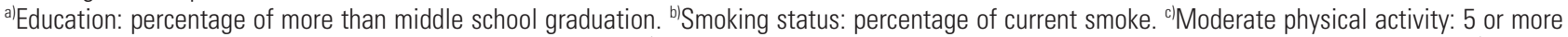
days of moderate-intensity activity of at least 30 min per day. ${ }^{d}$ Walking physical activity: 5 or more days of walking of at least 30 min per day. ${ }^{\text {elIncome: }}$ percentage of highest quartile.

$\mathrm{BMI}$, body mass index; SMI, skeletal muscle mass index; COPD, chronic obstructive pulmonary disease; PTH, parathyroid hormone; VitD, vitamin D; ALP, alkaline phosphatase; TG, triglyceride. 
In elderly women, total energy $(P<0.001)$, carbohydrates $(P<0.001)$, fat $(P<0.001)$, total protein $(P<0.001)$, and low dietary protein intake $(P=0.01)$ were significantly lower in the osteosarcopenia group than in the normal group (Table 3).
4. Dietary intake of total energy, carbohydrates, fats, and proteins by sarcopenic obesity vs. osteosarcopenia

In the elderly men, total energy $(P=0.042)$, fat $(P=0.015)$,

Table 2. Dietary intake of total energy, carbohydrates, fats, and proteins by presence of sarcopenia

\begin{tabular}{|c|c|c|c|c|c|c|}
\hline \multirow{2}{*}{ Variables } & \multicolumn{3}{|c|}{ Men } & \multicolumn{3}{|c|}{ Women } \\
\hline & Normal $(n=1,190)$ & Sarcopenia $(n=508)$ & $P$-value & Normal $(n=2,071)$ & Sarcopenia $(n=251)$ & $P$-value \\
\hline Total energy (kcal/day) & $1,956.7 \pm 695.6$ & $1,735.4 \pm 684.0$ & $<0.001$ & $1,437.6 \pm 540.7$ & $1,276.1 \pm 454.0$ & $<0.001$ \\
\hline Carbohydrates (g/day) & $340.6 \pm 112.8$ & $306.1 \pm 130.7$ & $<0.001$ & $276.6 \pm 103.6$ & $245.9 \pm 90.4$ & $<0.001$ \\
\hline Fat (g/day) & $28.6 \pm 24.0$ & $24.6 \pm 22.0$ & 0.001 & $17.8 \pm 15.5$ & $15.5 \pm 12.2$ & 0.009 \\
\hline Total proteins (g/day) & $65.7 \pm 31.8$ & $56.7 \pm 28.6$ & $<0.001$ & $45.3 \pm 23.2$ & $40.0 \pm 19.5$ & $<0.001$ \\
\hline NAR & $0.92 \pm 0.18$ & $0.87 \pm 0.19$ & $<0.001$ & & & \\
\hline Protein quartile ${ }^{a}(\mathrm{~g} / \mathrm{kg})$ & & & 0.197 & & & 0.274 \\
\hline $01(\%)$ & 11.2 & 14.5 & & 24.9 & 21.0 & \\
\hline $02(\%)$ & 21.9 & 18.9 & & 26.0 & 23.6 & \\
\hline $03(\%)$ & 27.0 & 28.1 & & 24.7 & 26.2 & \\
\hline $04(\%)$ & 40.0 & 38.5 & & 24.4 & 29.3 & \\
\hline Low dietary protein intake ${ }^{\text {b) }}$ & & & $<0.001$ & & & 0.046 \\
\hline Low intake (\%) & 43.4 & 57.7 & & 57.3 & 64.2 & \\
\hline Adequate intake (\%) & 56.6 & 42.3 & & 42.7 & 35.8 & \\
\hline Low protein intake $\mathrm{c}^{\mathrm{c}}$ & & & 0.340 & & & 0.022 \\
\hline Low intake (\%) & 57.2 & 59.8 & & 73.7 & 66.4 & \\
\hline Adequate intake (\%) & 42.8 & 40.2 & & 26.3 & 33.6 & \\
\hline
\end{tabular}

The data is presented as mean \pm standard deviation or percentage distribution of participants as appropriate.

${ }^{a}$ Men: $01<0.67,0.67 \leq 02<0.90,0.90 \leq 03<1.22,04 \geq 1.22$; Women: $01<0.53,0.53 \leq 02<0.75,0.75 \leq 03<1.02,04 \geq 1.02$ ). ${ }^{\text {bl } M e n: ~}<55 \mathrm{~g} / \mathrm{day}$; Women: $<45 \mathrm{~g} /$ day. ${ }^{\mathrm{c}}<1.0 \mathrm{~g} / \mathrm{kg} /$ day.

NAR, nutrient adequacy ratio.

Table 3. Dietary intake of total energy, carbohydrates, fats, and proteins by presence of osteosarcopenia

\begin{tabular}{|c|c|c|c|c|c|c|}
\hline \multirow{2}{*}{ Variables } & \multicolumn{3}{|c|}{ Men } & \multicolumn{3}{|c|}{ Women } \\
\hline & Normal $(n=1,470)$ & Osteosarcopenia $(n=112)$ & $P$-value & Normal $(n=2,013)$ & Osteosarcopenia $(n=153)$ & $P$-value \\
\hline Weight (kg) & $63.6 \pm 9.1$ & $52.7 \pm 8.7$ & $<0.001$ & $55.6 \pm 8.7$ & $44.9 \pm 6.0$ & $<0.001$ \\
\hline Total energy (kcal/day) & $1,908.0 \pm 694.3$ & $1,667.2 \pm 728.3$ & $<0.001$ & $1,436.9 \pm 539.3$ & $1,206.1 \pm 410.4$ & $<0.001$ \\
\hline Carbohydrates (g/day) & $333.3 \pm 119.5$ & $291.9 \pm 111.3$ & $<0.001$ & $276.2 \pm 103.5$ & $235.8 \pm 83.5$ & $<0.001$ \\
\hline Fat (g/day) & $27.9 \pm 23.9$ & $21.7 \pm 16.8$ & $<0.001$ & $17.9 \pm 15.5$ & $13.0 \pm 9.9$ & $<0.001$ \\
\hline Total proteins (g/day) & $63.9 \pm 31.1$ & $52.2 \pm 30.4$ & $<0.001$ & $45.3 \pm 23.1$ & $36.9 \pm 17.5$ & $<0.001$ \\
\hline NAR & $0.90 \pm 0.18$ & $0.93 \pm 0.13$ & 0.111 & & & \\
\hline Protein quartile ${ }^{a)}(\mathrm{g} / \mathrm{kg})$ & & & 0.432 & & & 0.990 \\
\hline $01(\%)$ & 11.9 & 15.2 & & 24.6 & 23.5 & \\
\hline $02(\%)$ & 20.7 & 25.0 & & 25.7 & 25.5 & \\
\hline $03(\%)$ & 27.6 & 24.1 & & 24.8 & 25.5 & \\
\hline $04(\%)$ & 39.9 & 35.7 & & 24.9 & 25.5 & \\
\hline Low dietary protein intake $\mathrm{e}^{\text {b) }}$ & & & $<0.001$ & & & 0.010 \\
\hline Low intake (\%) & 46.1 & 67.9 & & 57.3 & 68.0 & \\
\hline Adequate intake (\%) & 53.9 & 32.1 & & 42.7 & 32.0 & \\
\hline
\end{tabular}

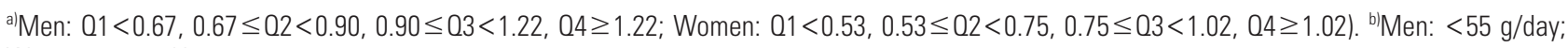
Women: $<45 \mathrm{~g} /$ day.

NAR, nutrient adequacy ratio. 
total protein $(P=0.037)$, and low dietary protein intake $(P=0.029)$ were significantly lower in the osteosarcopenia group than in the sarcopenic obesity.

However, none of the variables of dietary intake in the elderly women were significantly different between the osteosarcopenia group and the sarcopenic obesity (Table 4).

\section{Cut off value of protein intake for sarcopenia and osteosarcopenia}

The cut-off value for protein intake for sarcopenia was $57 \mathrm{~g} /$ day in men and $33 \mathrm{~g} /$ day in women (Fig. 2). The cutoff value of protein intake for osteosarcopenia was $54 \mathrm{~g} /$ day in men and $39 \mathrm{~g} /$ day in women (Fig. 3). The cut-off value of the adjusted weight of protein intake for sarcopenia

Table 4. Dietary intake of total energy, carbohydrates, fats, and proteins by sarcopenic obesity vs. osteosarcopenia

\begin{tabular}{|c|c|c|c|c|c|c|}
\hline \multirow[b]{2}{*}{ Variables } & \multicolumn{3}{|c|}{ Men } & \multicolumn{3}{|c|}{ Women } \\
\hline & $\begin{array}{l}\text { Sarcopenic obesity } \\
\qquad(n=44)\end{array}$ & $\begin{array}{l}\text { Osteosarcopenia } \\
\quad(n=106)\end{array}$ & $P$-value & $\begin{array}{l}\text { Sarcopenic obesity }{ }^{c)} \\
\qquad(n=6)\end{array}$ & $\begin{array}{l}\text { Osteosarcopenia } \\
\quad(n=148)\end{array}$ & $P$-value \\
\hline Weight (kg) & $70.9 \pm 6.8$ & $51.7 \pm 7.2$ & $<0.001$ & $60.5 \pm 5.6$ & $44.5 \pm 5.5$ & $<0.001$ \\
\hline Total energy (kcal/day) & $1,951.5 \pm 900.8$ & $1,661.7 \pm 735.4$ & 0.042 & $1,386.2 \pm 455.8$ & $1,200.3 \pm 415.2$ & 0.371 \\
\hline Carbohydrates (g/day) & $328.9 \pm 141.9$ & $290.3 \pm 111.8$ & 0.113 & $262.8 \pm 73.0$ & $235.4 \pm 84.7$ & 0.408 \\
\hline Fat (g/day) & $32.8 \pm 40.8$ & $21.4 \pm 16.4$ & 0.015 & $18.9 \pm 17.2$ & $12.8 \pm 9.9$ & 0.428 \\
\hline NAR & $0.89 \pm 0.17$ & $0.93 \pm 0.13$ & 0.069 & & & \\
\hline Total proteins (g/day) & $63.8 \pm 35.8$ & $51.7 \pm 30.3$ & 0.037 & $43.4 \pm 27.4$ & $36.9 \pm 27.4$ & 0.558 \\
\hline Protein quartile ${ }^{a)}(\mathrm{g} / \mathrm{kg})$ & & & 0.274 & & & 0.874 \\
\hline $01(\%)$ & 27.3 & 14.2 & & 33.3 & 24.3 & \\
\hline $02(\%)$ & 20.5 & 24.5 & & 33.3 & 25.0 & \\
\hline $03(\%)$ & 25.0 & 25.5 & & 16.7 & 25.0 & \\
\hline $04(\%)$ & 27.3 & 35.8 & & 16.7 & 25.7 & \\
\hline Low dietary protein intake $e^{\text {b) }}$ & & & 0.029 & & & 0.907 \\
\hline Low intake (\%) & 23.2 & 40.0 & & 67.7 & 68.9 & \\
\hline Adequate intake (\%) & 76.8 & 60.0 & & 33.3 & 31.1 & \\
\hline
\end{tabular}

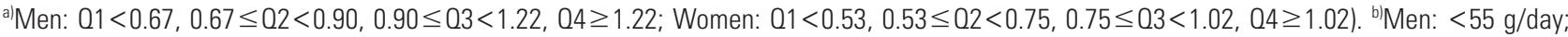

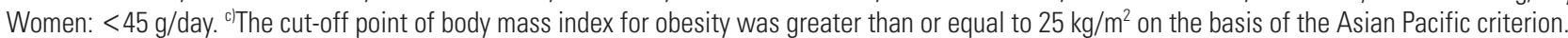
NAR, nutrient adequacy ratio.
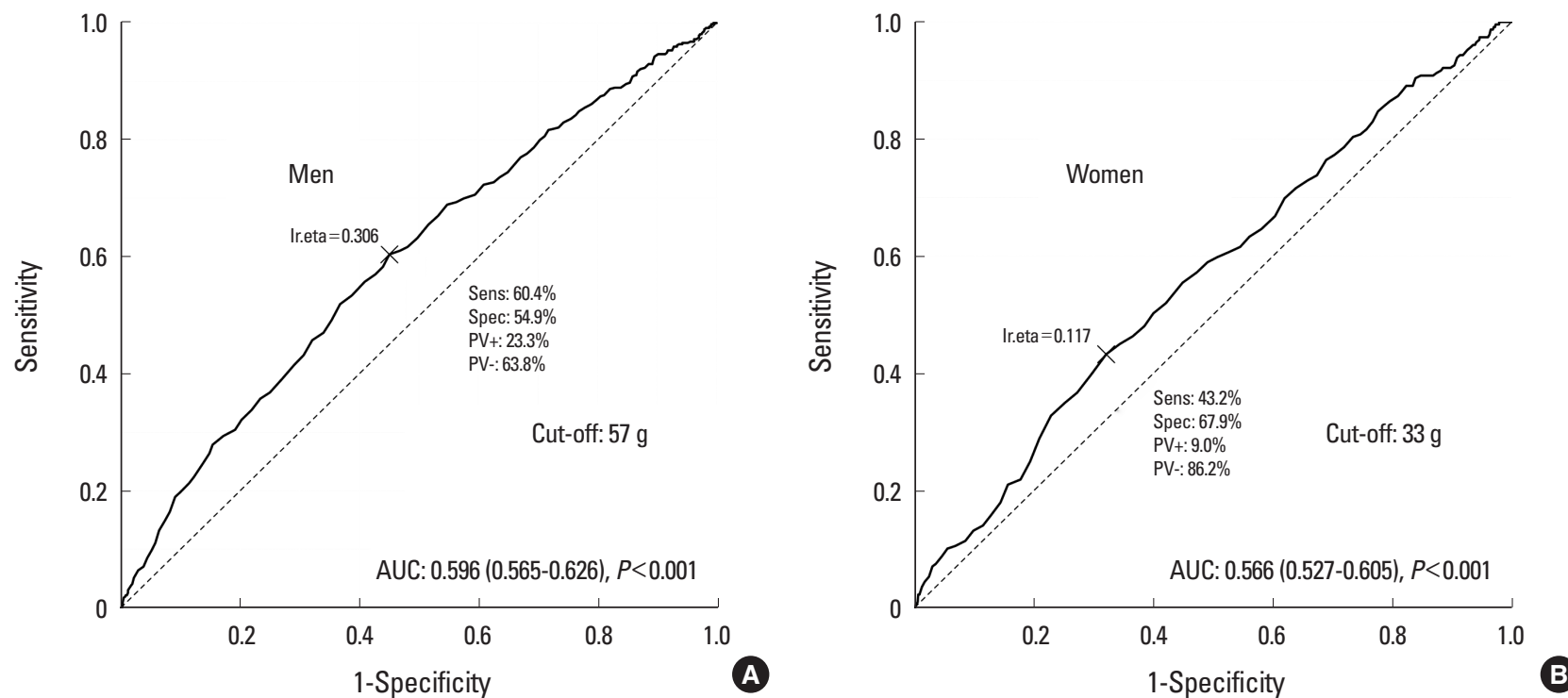

Fig. 2. Cut-off value of protein intake for sarcopenia. AUC, area under the curve. 
was $0.58 \mathrm{~g} / \mathrm{kg} / \mathrm{day}$ in men and $0.98 \mathrm{~g} / \mathrm{kg} /$ day in women (Fig. 4). The cut-off value of the adjusted weight for protein intake for osteosarcopenia was $0.8 \mathrm{~g} / \mathrm{kg} /$ day in men and $0.5 \mathrm{~g} / \mathrm{kg} /$ day in women (Fig. 5).

\section{DISCUSSION}

This descriptive observational study demonstrated a relationship between malnutrition and sarcopenia. Comparing gender-specific demographic characteristics, both gen- ders in sarcopenia were older. BMI and appendicular SMI were lower only in women with sarcopenia. However, medical comorbidity was more prominent in men with sarcopenia. The principal findings are that total energy, carbohydrates, fat, total protein and dietary intake protein in both genders with sarcopenia and osteosarcopenia were significantly lower than in normal populations. In this study, the cut-off points for the protein intake of men and women for osteosarcopenia were 0.8 and $0.5 \mathrm{~g} / \mathrm{kg} /$ day, respectively. However, this is not a reference result for the mini-
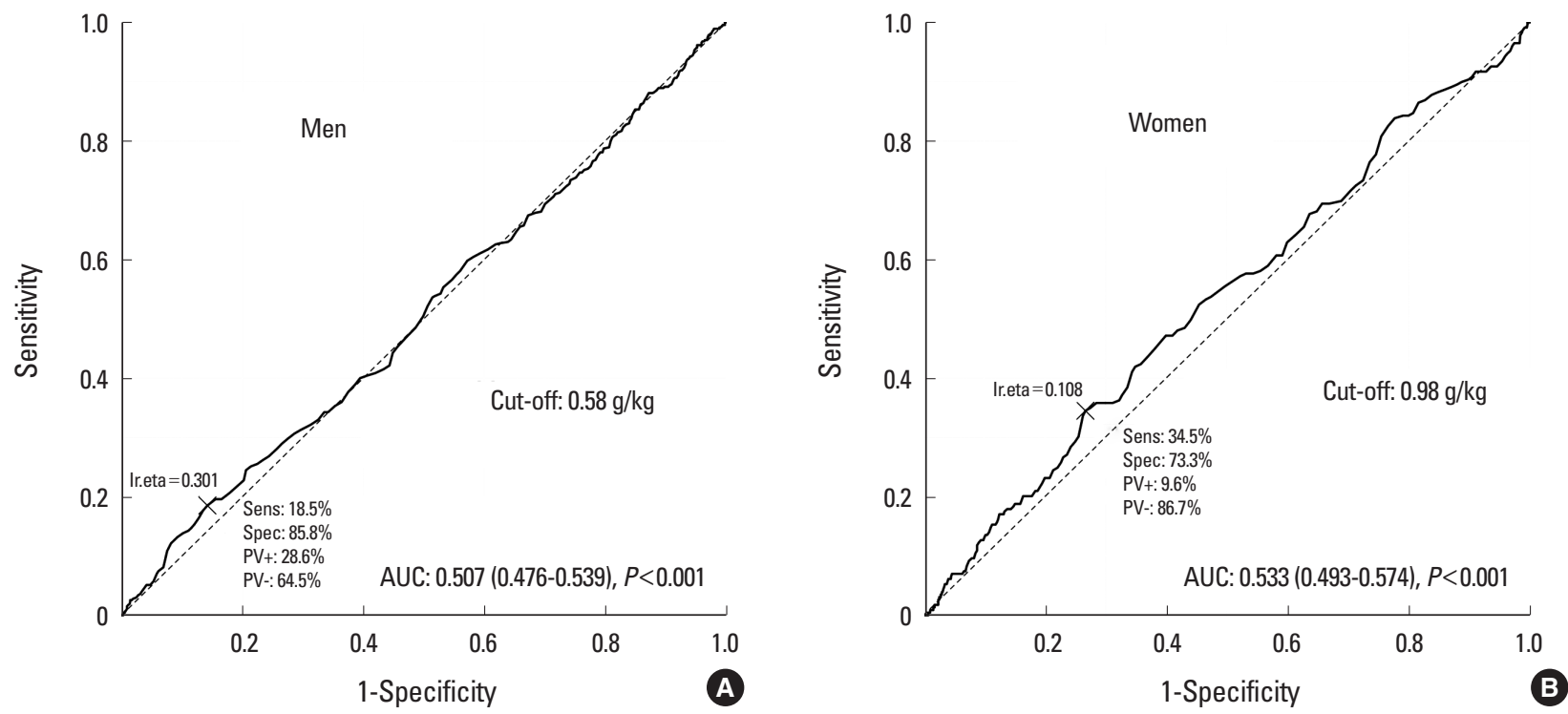

Fig. 3. Cut-off value of protein intake for osteosarcopenia. AUC, area under the curve.
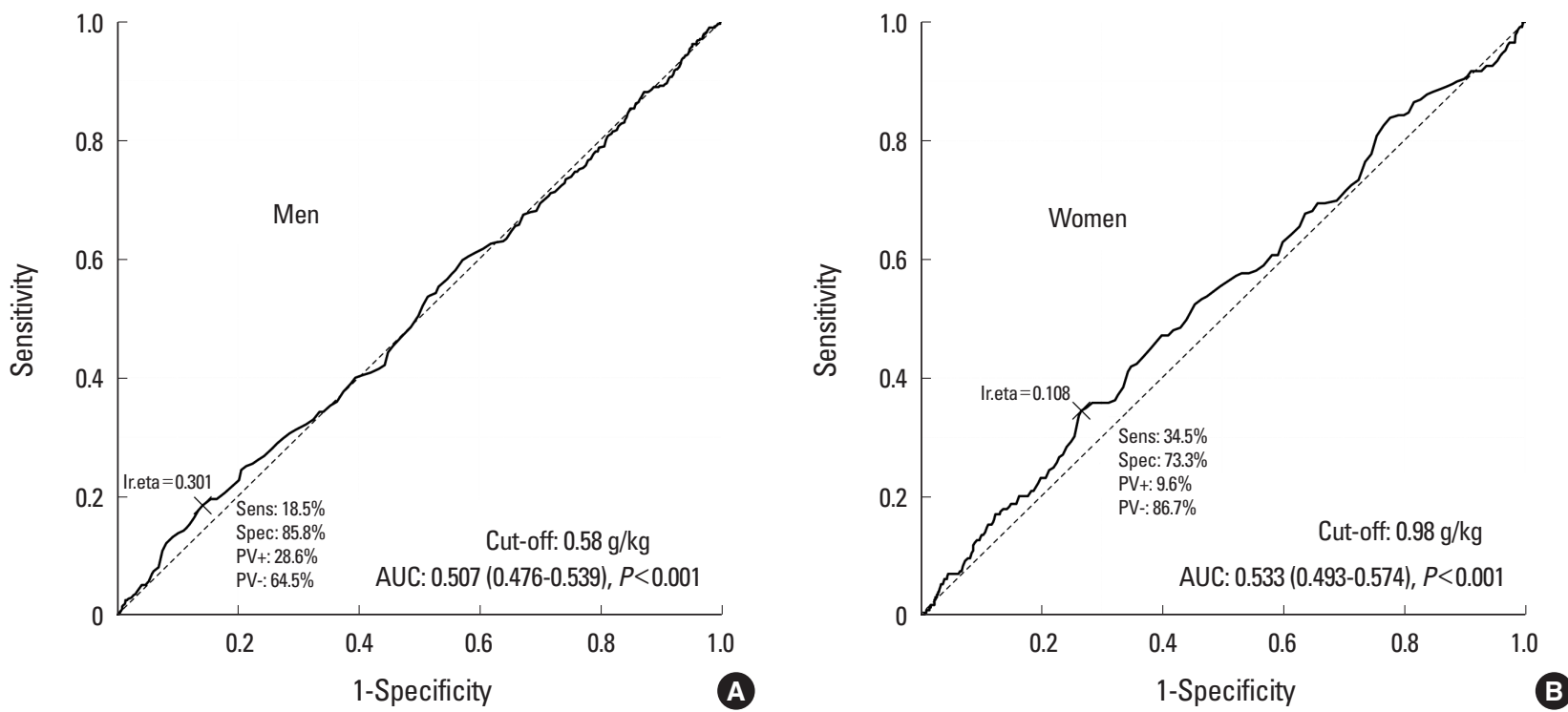

Fig. 4. Cut-off value of adjusted weight of protein intake for sarcopenia. AUC, area under the curve. 

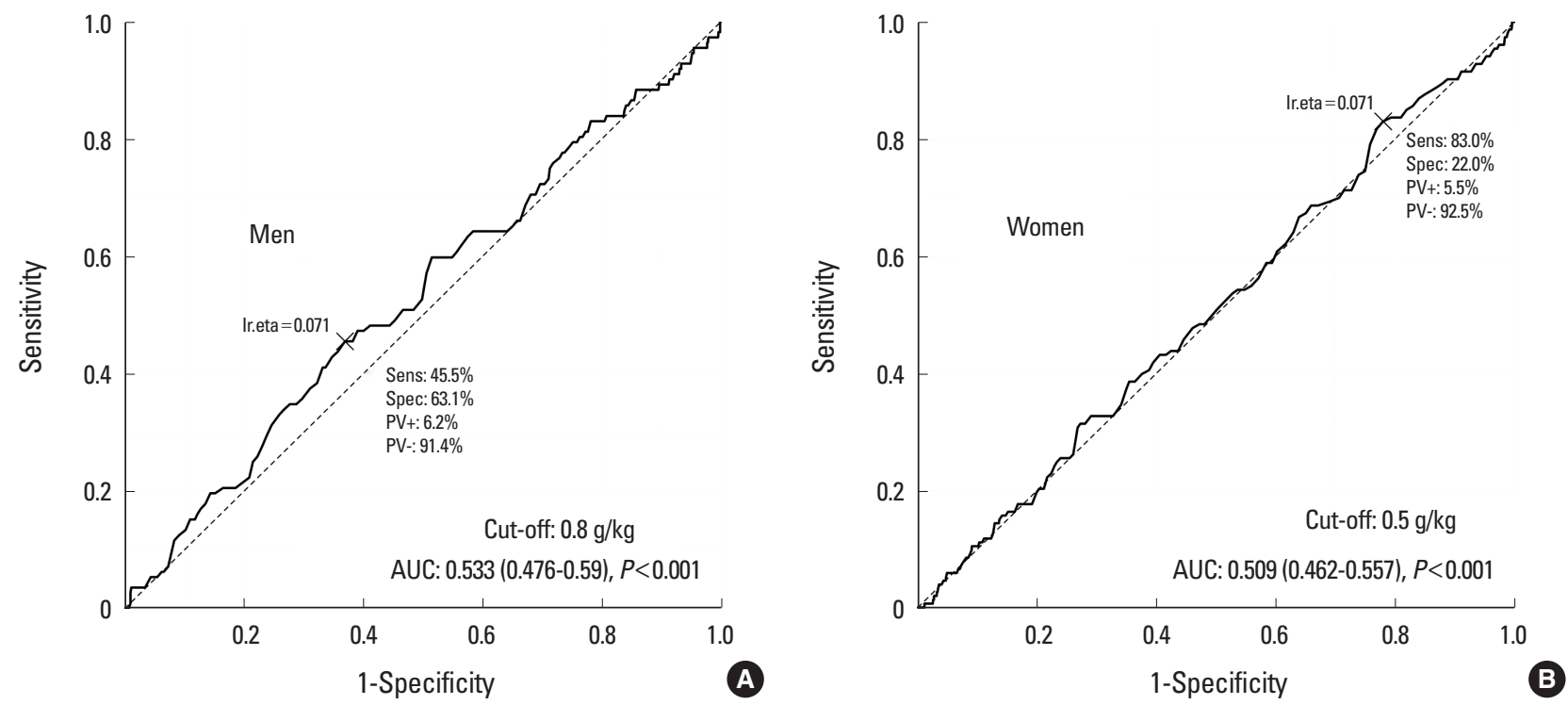

Fig. 5. Cut-off value of adjusted weight of protein intake for osteosarcopenia AUC, area under the curve.

mum recommended amount of protein and should be interpreted only as a cut-off point that increases the risk of osteosarcopenia. In addition, an analysis comparing sarcopenic obesity is not possible with the design of this study and will have to be done with additional samples and detailed nutritional assessment in the future.

In present study, both genders of sarcopenia and osteosarcopenia had lower dietary energy intake and total energy. Despite studies of the relationship between lower protein intake and sarcopenia, this finding is consonant with previous studies. Huang et al. evaluated the association between pre-sarcopenia status and lower protein intake using a population of 327 community-dwelling elderly. They found that participants with diets in the lowest quartile of total protein density were at 3.3 times higher risk for low muscle mass.[17] Several longitudinal studies demonstrated that adequate dietary protein maintains lean mass and strength in elderly populations.[16,17]

Osteosarcopenia and sarcopenic obesity are most commonly studied. Although diagnostic Osteosarcopenia and sarcopenic obesity are the most commonly studied. Although the diagnostic definitions of the 2 representative types of sarcopenia are similar, etiologic factors might differ between the 2 types. Especially sarcopenic obesity is more related to metabolic syndromes and more commonly occurs in patients with diabetes. However, osteosarcopenia is mostly related to the elderly population with osteoporosis. In subgroup analysis, we found that poor di- etary protein intake was more related to osteosarcopenia in this study. Although Oh et al. [18] reported that the sarcopenic-obesity group was lower in physical activity, protein intake, and vitamin D level, they did not compare them with the osteosarcopenic group. Our findings are commonly found in patients with hip fractures, which are known to be a key phenotype of sarcopenia and osteosarcopenia. Poor protein intake and malnutrition are frequently accompanied in patients with osteosarcopenia. In this group, nutritional status should be evaluated, and nutritional support was proven to improve functional outcomes.[19,20]

This study has several limitations. First, the criteria for diagnosing sarcopenia were applied as in the previous the AWGS guideline. Given the limitation of the KNHANES data, which include only skeletal muscle mass, we analyzed protein intake by applying the diagnostic criteria for presarcopenia. Further research will require analysis of protein intake by the AWGS-II, which includes grip strength and physical performance.

Second, protein and nutrient intake were evaluated using only the self-reported questionnaire. In particular, in the elderly group, questionnaire nutritional assessment including 24-hr recall may not be accurate. In the near future, it should be accurately evaluated using nutritional values measured by means of community cohort and hospital cohort studies. Third, analysis and meaning could not be given, because the number of groups overlapping the 3 diseases (osteoporosis+sarcopenia+obesity) in common was 
small. Further analysis of the nutritional status of patients with all 3 diagnostic categories by means of different cohorts is required. Finally, the sarcopenia obesity group is too small to find significance compared to the osteosarcopenia group.

In conclusion, a comprehensive dietary assessment for the detection of nutritional deficits that predispose to or aggravate muscle atrophy is important for establishing a treatment plan for patients with malnutrition.

\section{DECLARATION}

\section{Acknowledgments}

This work was carried out with the support of "Cooperative Research Program for Agriculture Science and Technology Development (Project No. PJ014155052019)" Rural Development Administration, Republic of Korea.

\section{Availability of data and material}

Cross-sectional data from the Korea National Health and Nutrition Examination Survey by Korea Centers for Disease Control and Prevention and Korean Ministry of Health and Welfare. The data, therefore, is freely available at: https:// knhanes.cdc.go.kr/knhanes/index.do.

\section{Ethics approval and consent to participate}

The protocol of this study for performing an analysis of the 2008-2011 Korean National Health and Nutrition Examination Survey (KNHANES) data was reviewed and approved by the Institutional Review Board (IRB) of Korea Centers for Disease Control and Prevention (KCDC) (Approval No. 2008-04EXP-01-C, 2009-01CON-03-C, 201002CON-21-C, and 2011-02CON-06-C). Informed consent was obtained from all participants when the 2008 KNHANES, 2009 KNHANES, 2010 KNHANES and 2011 KNHANES were conducted.

\section{Conflict of interest}

No potential conflict of interest relevant to this article was reported.

\section{ORCID}

Jun-II Yoo https://orcid.org/0000-0002-3575-4123 Yong-Geun Park

\section{REFERENCES}

1. Marcell TJ. Sarcopenia: causes, consequences, and preventions. J Gerontol A Biol Sci Med Sci 2003;58:M911-6. http:// dx.doi.org/10.1093/gerona/58.10.m911.

2. Vandewoude MF, Alish CJ, Sauer AC, et al. Malnutrition-sarcopenia syndrome: is this the future of nutrition screening and assessment for older adults? J Aging Res 2012;2012: 651570. http://dx.doi.org/10.1155/2012/651570.

3. Binkley N, Buehring B. Beyond FRAX: it's time to consider "sarco-osteopenia". J Clin Densitom 2009;12:413-6. http:// dx.doi.org/10.1016/j.jocd.2009.06.004.

4. Kull M, Kallikorm R, Lember M. Impact of a new sarco-osteopenia definition on health-related quality of life in a population-based cohort in Northern Europe. J Clin Densitom 2012;15:32-8. http://dx.doi.org/10.1016/j.jocd.2011. 08.007.

5. Janssen I. Influence of sarcopenia on the development of physical disability: the Cardiovascular Health Study. J Am Geriatr Soc 2006;54:56-62. http://dx.doi.org/10.1111/j. 1532-5415.2005.00540.x

6. Schneider SM, Veyres P, Pivot X, et al. Malnutrition is an independent factor associated with nosocomial infections. Br J Nutr 2004;92:105-11. http://dx.doi.org/10.1079/bjn20041152

7. Edington J, Boorman J, Durrant ER, et al. Prevalence of malnutrition on admission to four hospitals in England. The Malnutrition Prevalence Group. Clin Nutr 2000;19:1915. http://dx.doi.org/10.1054/clnu.1999.0121.

8. Cosquéric G, Sebag A, Ducolombier C, et al. Sarcopenia is predictive of nosocomial infection in care of the elderly. $\mathrm{Br}$ J Nutr 2006;96:895-901. http://dx.doi.org/10.1017/bjn20061943.

9. Raguso CA, Kyle U, Kossovsky MP, et al. A 3-year longitudinal study on body composition changes in the elderly: role of physical exercise. Clin Nutr 2006;25:573-80. http:// dx.doi.org/10.1016/j.clnu.2005.10.013.

10. Colbert LH, Visser M, Simonsick EM, et al. Physical activity, exercise, and inflammatory markers in older adults: findings from the Health, Aging and Body Composition Study. J Am Geriatr Soc 2004;52:1098-104. http://dx.doi.org/10. 1111/j.1532-5415.2004.52307.x.

11. Gabriel DA, Kamen G, Frost G. Neural adaptations to resistive exercise: mechanisms and recommendations for training practices. Sports Med 2006;36:133-49. http://dx.doi. 
org/10.2165/00007256-200636020-00004.

12. Blundell JE, King NA. Physical activity and regulation of food intake: current evidence. Med Sci Sports Exerc 1999; 31:S573-83. http://dx.doi.org/10.1097/00005768-199911001-00015.

13. Rural Development Administration. The national standard food composition table 8th revisiom. 2011 [cited by 2020 Nov 5]. Available from: https://koreanfood.rda.go.kr:2360/ eng/fctFoodSrchEng/list.

14. Lewiecki EM, Gordon CM, Baim S, et al. International society for clinical densitometry 2007 adult and pediatric official positions. Bone 2008;43:1115-21. http://dx.doi.org/10. 1016/j.bone.2008.08.106.

15. Chen LK, Liu LK, Woo J, et al. Sarcopenia in Asia: consensus report of the Asian working group for sarcopenia. J Am Med Dir Assoc 2014;15:95-101. http://dx.doi.org/10.1016/ j.jamda.2013.11.025.

16. Ministry of Health and Welfare. The Korean Nutrition Society. Dietary reference intakes for Koreans 2015. Sejong: Ministry of Health and Welfare; 2015.
17. Huang RY, Yang KC, Chang HH, et al. The Association between total protein and vegetable protein intake and low muscle mass among the community-dwelling elderly population in Northern Taiwan. Nutrients 2016;8. http:// dx.doi.org/10.3390/nu8060373.

18. Oh C, Jeon BH, Reid Storm SN, et al. The most effective factors to offset sarcopenia and obesity in the older Korean: Physical activity, vitamin $D$, and protein intake. Nutrition 2017;33:169-73. http://dx.doi.org/10.1016/j.nut.2016.06. 004.

19. Inoue T, Misu S, Tanaka T, et al. Pre-fracture nutritional status is predictive of functional status at discharge during the acute phase with hip fracture patients: a multicenter prospective cohort study. Clin Nutr 2017;36:1320-5. http:// dx.doi.org/10.1016/j.clnu.2016.08.021.

20. Koren-Hakim T, Weiss A, Hershkovitz A, et al. Comparing the adequacy of the MNA-SF, NRS-2002 and MUST nutritional tools in assessing malnutrition in hip fracture operated elderly patients. Clin Nutr 2017;36:912. http://dx.doi. org/10.1016/j.clnu.2017.01.018. 